\title{
Experimental Study of Efficiency of Tertapeptide Lysil-Glutamyl-Aspartyl- Proline Using the Model of Benign Prostatic Hyperplasia
}

\author{
Tatyana Gennadyevna Borovskaya, Tatyana Ivanovna Fomina, \\ Juliya Aexandrovna Shchemerova, Marina Evgenyevna Poluektova, \\ Anna Vladimirovna Vychuzhanina, Svetlana Ivanovna Kamalova, \\ Lubov Aexandrovna Ermolaeva
}

The Goldberg Research Institute of Pharmacology, Tomsk, Russia

Email: repropharm@yandex.ru

Received 19 May 2014; revised 15 June 2014; accepted 10 July 2014

Copyright (C) 2014 by authors and Scientific Research Publishing Inc.

This work is licensed under the Creative Commons Attribution International License (CC BY).

http://creativecommons.org/licenses/by/4.0/

(c) (i)

\begin{abstract}
Experimental evaluation of efficiency of a new prostatotropic medication tertapeptide lysil-glutamyl-aspartyl-proline (Lys-Glu-Asp-Pro) in treatment of benign prostatic hyperplasia was performed in Wistar rats. The efficiency of the medication was compared with that one of injections of the Serenoa repens extract. The investigation showed the statistically significant decrease in the square of the epithelium of acini. The same effect of similar severity was obtained when the Serenoa repens extract was applied. Tertapeptide Lys-Glu-Asp-Pro, in difference from Serenoa repens extract, also resulted in weight loss and volume decrease of the prostate gland.
\end{abstract}

\section{Keywords}

Benign Prostatic Hyperplasia, Rats, Tertapeptide Lysil-Glutamyl-Aspartyl-Proline

\section{Introduction}

Benign prostatic hyperplasia (BPH) - is one of the most widespread urologic diseases in older men [1] [2]. This dishormonal disease with signs of inflammatory reaction is difficult to take conservative treatment and significantly reduces the life quality of the patients [3]. The arsenal of pharmacotherapy for BPH accounts more than 10 groups of drugs. The drugs of choice are alpha 1-blockers and inhibitors of 5 alpha-reductase [4]. However, 
these groups of drugs have a number of side effects. The most popular prostatotropic drugs include the medications based on extract of Serenoa repens [5]. Despite the wide range of pharmacotherapy preparations, incidence of BPH is not reduced over time. This fact demands the search for new drugs for treatment of this disease. At present, a new medication Prostamaks is obtained by the method of peptide synthesis. This medication belongs to bioregulatory peptides. It is a tetrapeptide, with a positive tissue-specific effect on prostate. The results of experimental and clinical studies of bioregulatory peptides show that they are involved directly in the processes of tissue-specific regulation of gene expression and biosynthesis as well as in the processes neurohumoral regulation of prostate tissue. The present article presents the results of experimental study of efficiency of Tertapeptide Lys-Glu-Asp-Pro using the model BPH caused by long-term administration of sulpiride to animals of reproductive age [6].

\section{Material and Methods}

The experiments were preformed in 40 white male Wistar rats (age is 10 months, weight is 450 - 660 g), which include control group (10) and intaxct group (10). The rats were obtained from the breeding rat nursery at Biomedical modeling Department of The Goldberg Research Institute of Pharmacology (Tomsk). The rats were oused in accordance with the rules adopted by the European Convention for the Protection of Pet Animals (Strasbourg, 1987), which are used for experimental and other scientific purposes.

BPH was induced by hyperprolactinemia. For this purpose the male rats were daily injected subcutaneously with sulpiride (Eglonylum; The Sanofi-Synthelabo Group, France) during 60 days [6] [7]. As a comparison drug was used extract of Serenoa repens-Prostamol Uno (Berlin-Chemie/Menarini Pharma GmbH, Germany). All the test animals were divided into the following groups: group I-intact rats; control group II-got sulpiride daily intraperitoneal in dose of $40 \mathrm{mg} / \mathrm{kg}$ + solvent daily intraperitoneally with $0.5 \mathrm{ml} / 100 \mathrm{~g}$ during 60 dais; group III-got sulpiride (daily, intraperitoneally in dose of $40 \mathrm{mg} / \mathrm{kg}$ ) + Tertapeptide Lys-Glu-Asp-Pro (daily, with intramuscular dose of $20 \mathrm{mg} / \mathrm{kg}$ for 60 days); group IV—got sulpiride (daily, intraperitoneally in dose of 40 $\mathrm{mg} / \mathrm{kg}$ ) + extract of Serenoa repens (daily in oral dose of $50 \mathrm{mg} / \mathrm{kg}$ and for 60 days).

At the end of the course the body weight was measured and the rats were euthanized in a $\mathrm{CO}_{2}$ chamber. Then, taking into account that sulpiride causes development of BPH in the side lobe of rats and does not affect the morphology of the anterior and posterior lobes [8], the lateral part of the prostate gland was dissected. Its weight and volume were measured and weighting coefficients were calculated.

The experimentally obtained biological material was used for histological study then. The lateral part of prostate was fixed in $10 \%$ formalin, embedded in paraffin, and sectioned with a thickness of 5 microns. Deparaffinized sections were stained with hematoxylin and eosin.

The area of epithelial parts and lumen of adenomere were measured on a standard square of histological section by computer graphic analysis (micrographs of 10 consecutive fields of view, performed with videocamera "AxioCam Erc5s" set up in microscope "AxioLab A1" (lens $\times 10$, ocular $\times 10$ ) and software developed by "AxioVision LE” (Carl Zeisis AG, Germany).

The results were processed using the method of variation statistics and U nonparametric Mann-Whitney criterion.

\section{Results and Discussion}

The carried out experimental study showed (Figure 1) that administration of sulpiride for 2 months resulted in significant increase (more than 2 times) of the mass of lateral part of prostate, as compared to the intact rats group I. The weight coefficient was significantly increased by almost 2.5 times. The volume of the lateral part of prostate was also significantly increased by 2 times. Similar changes were obtained in experiments performed by V. G. Bespalov et al. (2003) [9].

In rats of the group III (sulpiride + Tertapeptide Lys-Glu-Asp-Pro) the same parameters were significantly decreased as to control group II (sulpiride): mass of the lateral part of prostate-by $24 \%$, weight coefficient-by $25 \%$, volume-by $40 \%$.

In rats of the group IV (sulpiride + extract of Serenoa repens) the parameters (mass of the lateral part of prostate, weight coefficient, volume) were not different from those in rats of the control group I (Figure 1).

The obtained experimental results on extract of Serenoa repens agreed with the data of experimental and clinical observations. For example V.G. Bespalov et al. (2003) showed that Prostamol Uno does not lead to statisti- 


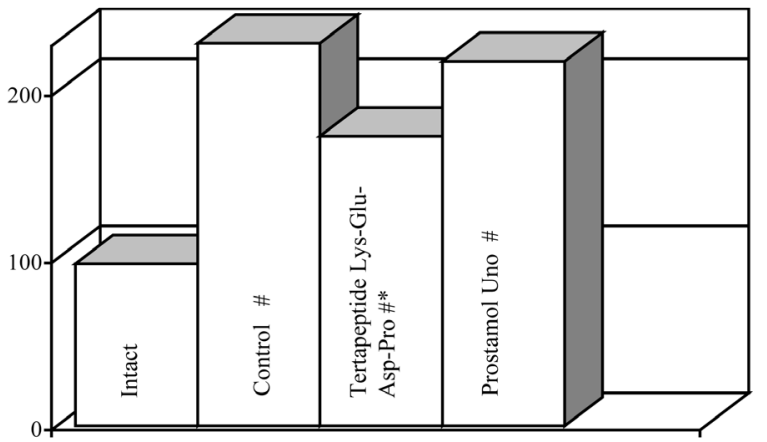

(a)

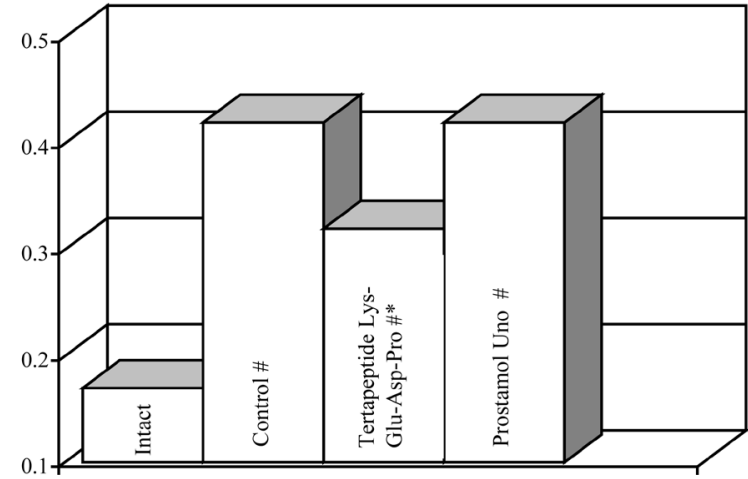

(b)

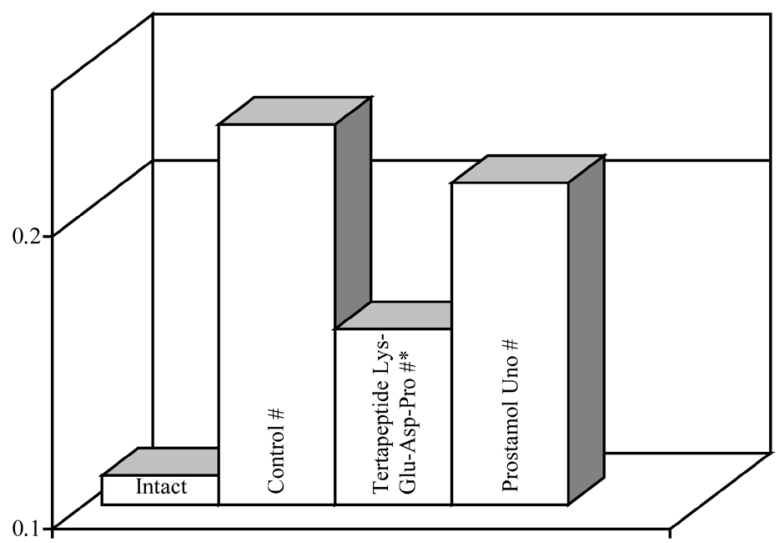

(c)

Figure 1. Influence of Tertapeptide Lys-Glu-Asp-Pro on mass (a) weight coefficient (b), and volume (c) of prostate. ${ }^{*} \mathrm{P}_{\mathrm{IV}-\mathrm{II}} \leq 0.05 ;{ }^{\#} \mathrm{P}_{\mathrm{IV}-\mathrm{I}} \leq 0.05$.

cally significant reduction in prostate volume [9].

Microscopic study of the lateral lobes of prostate in intact rats did not show any pathological changes. The termination parts of the lateral lobe of prostate were the acini lined by a single layer of columnar epithelium and filled with different amounts of homogeneous secret. Between acini there were unformed loose layers of connective tissue, blood vessels and cellular elements. In prostate stroma there were found leukocytes, fibroblasts, macrophages, and mast and isolated smooth muscle cells. All rats treated with sulpiride showed the signs of nodular benign prostatic hyperplasia. As a rule, the administration of sulpiride caused development of adenomatous hyperplasia in all of the rats. It shows acinar structures surrounded by connective tissue layers. In acini the papillary epithelial proliferation were observed. Similar morphological changes were found by the other authors in rats under administration of sulpiride [10].

Measurements of the glandular epithelium area showed that it was 1.6 times higher than that one in intact rats (Figure 2). The area of epithelial acini was decreased. The area of prostate stroma was significantly increased. Furthermore, in almost all rats sulpiride caused the development of inflammatory cell infiltration of the interstitium (usually by macrophages and lymphocytes) as well as the appearance of terminate parts with enlarged gap filled with large amount of neutrophils and desquamated epithelium, that agrees with the data obtained by T. G. Borovskaya et al. (2003) [10]. Taking into account that sulpiride causes hyperprolactinemia, the identified changes are obviously the result of hormone-induced inflammatory response.

The relative area of prostate acini epithelium was decreased by $22.4 \%$ in rats of the group III (sulpiride + Tertapeptide Lys-Glu-Asp-Pro) as compared to that in rats of the control group II (sulpiride), Figure 2(a). It should be noted that the other researchers suggests that the main morphological substrate proving the effectiveness of therapy of BPH is epithelial atrophy [11]. The space between acini in the experimental group III tended to be higher, and the area of connective tissue streaks stayed almost unchanged as compared to the control group II, Figure 2(b), Figure 2(c). 


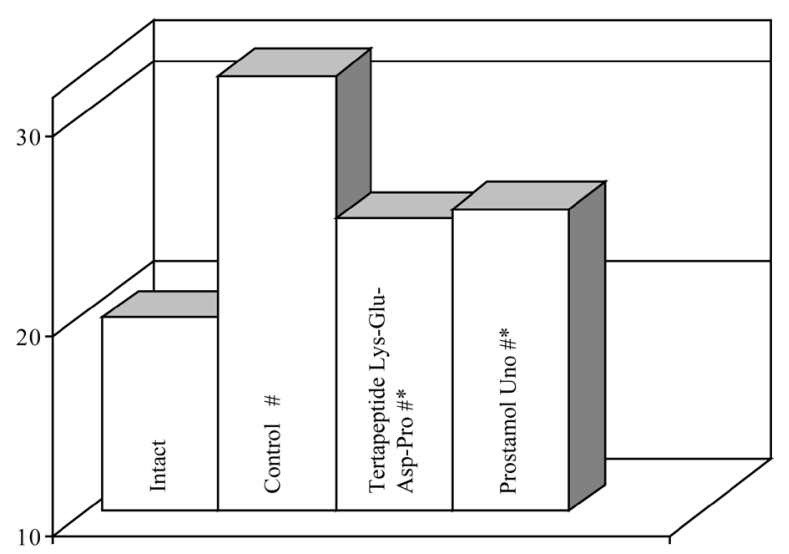

(a)

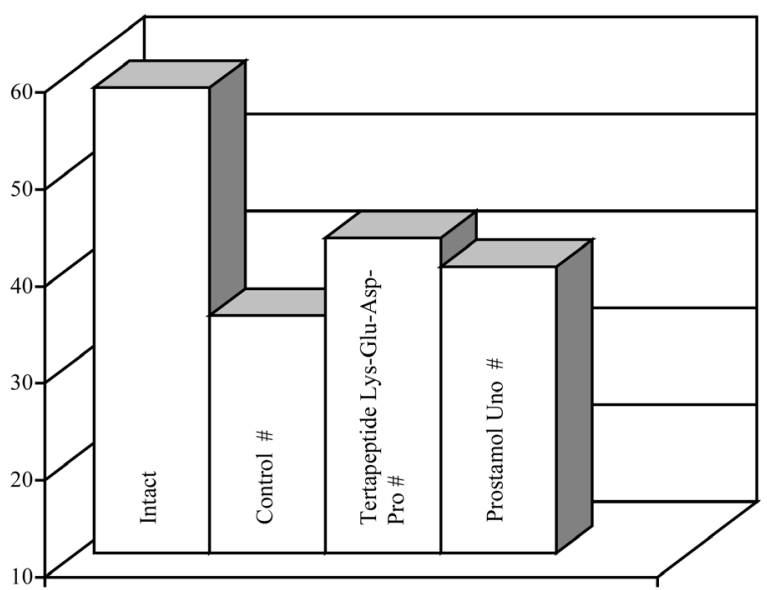

(b)

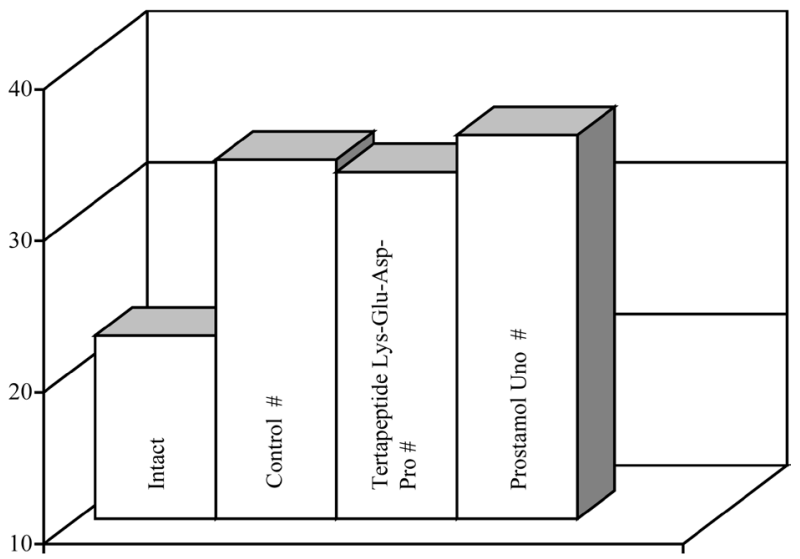

(c)

Figure 2. Influence of Tertapeptide Lys-Glu-Asp-Pro on morphological parameters of the lateral lobes of the prostate: (a) Area of acini epithelium; (b) Area of the gap between acini; (c) Stromal area; relation to the standard cut area in \%. ${ }^{*} \mathrm{P}_{\mathrm{IV}-\mathrm{II}} \leq 0.05 ;{ }^{*} \mathrm{P}_{\mathrm{IV}-\mathrm{I}} \leq 0.05$.

The intensity of inflammatory cell infiltration in the interlayers of prostate connective tissue was decreased. It was transformed from diffused to localized nature that indicates the anti-inflammatory effect of the investigated drug.

Administration of compared drug led to decrease area of area of epithelial acini as compared to the control group II. This agrees with the literature [8] [10]. Antiproliferative effect of extract of Serenoa repens in this category was comparable to that of Tertapeptide Lys-Glu-Asp-Pro.

\section{Conclusion}

The obtained data proved the fact that Tertapeptide Lys-Glu-Asp-Pro prevented the increase in mass, volume and weight coefficient of lateral lobes of the rat prostate, induced by administration of sulpiride. The performed experiments did not show this effect of Serenoa repens. Tertapeptide Lys-Glu-Asp-Pro also led to decrease in the area of epithelial acini. Its antiproliferative effects were similar to those of Serenoa repens. Thus, the drug Tertapeptide Lys-Glu-Asp-Pro was proved to be effective medication for therapy of BPH in experimental rats.

\section{References}

[1] Kirby, R. (2011) Improving Lower Urinary Tract Symptoms in BPH. Practitioner, 255, 15-19.

[2] Stroup, S.P., Palazzi-Churas, K., Kopp, R.P. and Parsons, J.K. (2012) Trends in Adverse Events of Benign Prostatic Hyperplasia (BPH). BJU International, 109, 84-87. http://dx.doi.org/10.1111/j.1464-410X.2011.10250.x 
[3] Vertkin, A.L., Rodukova, I.S., Galkin, I.V. and Arinina, E.N. (2009) Not Just a Prostate: Problems of Benign Prostatic Hyperplasia in Elderly. Pharmateca, 9, 50-55.

[4] Oelke, M., Kuczyk, M.A. and Herrmann, T.R. (2009) Medikamentose Therapie der Benignen Prostatahyperplasie. Urologe, 48, 1365-1377. http://dx.doi.org/10.1007/s00120-009-2141-y

[5] Carraro, J.C., Raynaud, J.R., Koch, G., et al. (1996) Comparison of Phytotherapy (Permixon) with Finasteride in Treatment of Benign Prostatic Hyperplasia: A Randomized International Study of 1098 Patients. Prostate, 29, 231-240. http://dx.doi.org/10.1002/(SICI)1097-0045(199610)29:4<231::AID-PROS4>3.0.CO;2-E

[6] Van Coppenolle, F., Le Bourhis, X., Carpentier, F., Delaby, G., Cousse, H., Raynaud, J.P., Dupouy, J.P. and Prevarskaya, N. (2000) Pharmacological Effects of Lipidosterolic Extract of Serenoa repens (Permixon) on Rat Prostate Hyperplasia Induced by Hyperprolactinemia: Comparison with Finasteride. Prostate, 43, 49-58. http://dx.doi.org/10.1002/(SICI)1097-0045(20000401)43:1<49::AID-PROS7>3.0.CO;2-J

[7] Borovskaya, T.G., Pakhomova, A.V., Vychuzhanina, A.V., Poluektova, M.T. and Fomina, T.I. (2013) Experimental Studying of the Drug Efficiency Prostamax in the Therapy of Chronic Aseptic Prostatitis and Its Complications. Modern Research in Inflammation, 2, 54-58.

[8] Marks, L.S., Epstein, J.I., Partin, A.W., Simon, I., et al. (2000) Effects of a Saw Palmetto Herbal Blend in Men with Symptomatic Benign Prostatic Hyperplasia. Journal of Urology, 163, 1451-1456. http://dx.doi.org/10.1016/S0022-5347(05)67641-0

[9] Bespalov, V.G., Murazov, J.G., Kuzhanov, A.A. and Semenov, A.L. (2013) Comparative Study of Prostatotropic Effects of Coniferous Provitamin Concentrate and Extract of Serenoa repens Based on the Model of Benign Prostatic Hyperplasia in Rats. Exp Clin Urology, 2, 30-34.

[10] Borovskaya, T.G., Fomina, T.I., Ermolaeva, L.A., Vychuzhanina, A.V., Pakhomova, A.V., Poluektova, M.E. and Shchemerova, Y.A. (2013) Comparative Evaluation of the Efficiency of Prostatotropic Agents of Natural Origin in Experimental Benign Prostatic Hyperplasia. Bulletin of Experimental Biology and Medicine, 155, 73-77. http://dx.doi.org/10.1007/s10517-013-2081-9

[11] Volkov, A.A., Voronova, O.V., Petrichko, M.I., Budnik, N.V. and Dukhin, A.R. (2012) Morphological Alterations of Prostate Tissue, upon Dutasteride Therapy Influence. Fundamental Research, 15, 36-39. 
Scientific Research Publishing (SCIRP) is one of the largest Open Access journal publishers. It is currently publishing more than 200 open access, online, peer-reviewed journals covering a wide range of academic disciplines. SCIRP serves the worldwide academic communities and contributes to the progress and application of science with its publication.

Other selected journals from SCIRP are listed as below. Submit your manuscript to us via either submit@scirp.org or Online Submission Portal.
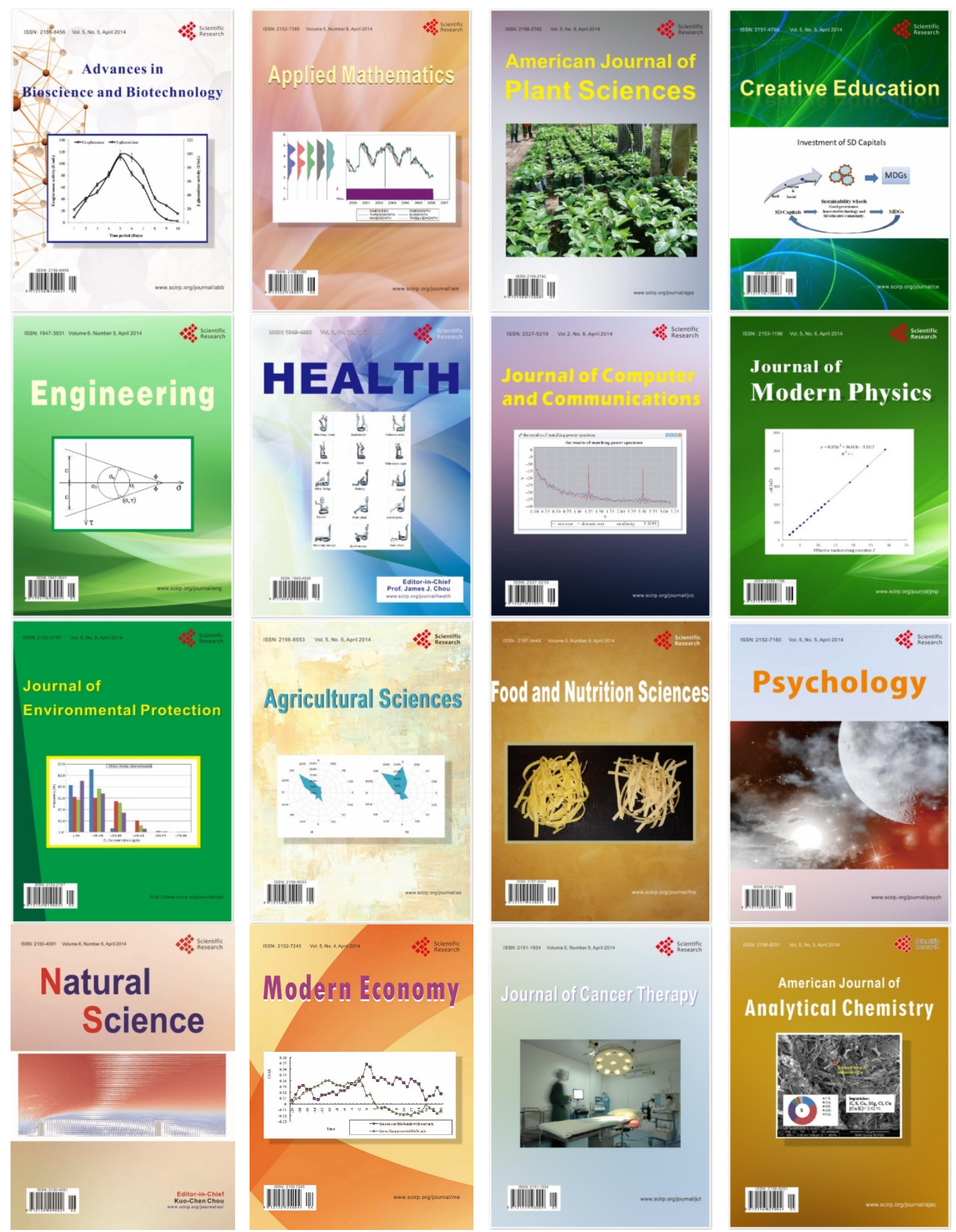